УДК 541.182

МЕТОДЫ ПОЛУЧЕНИЯ И ИССЛЕДОВАНИЯ

БЕНЗИНО-ЭТАНОЛЬНОЙ ЭМУЛЬСИИ

\title{
METHODS OF GASOLINE-ETHANOL EMULSION \\ PRODUCTION AND RESEARCH
}

Т.Р. Гареев, А.Т. Гильмутдинов, И.Г. Лапшин

Уфимский государственный нефтяной технический университет, г. Уфа, Российская Федерация

Timur R. Gareev, Amir T. Gilmutdinov, Igor G. Lapshin

Ufa State Petroleum Technological University, Ufa, Russian Federation

\section{e-mail: timur285@mail.ru, klods2010@yandex.ru}

Аннотация. В статье приведены общие сведения о водотопливной эмульсии, помогающей снизить вредные выбросы в атмосферу, повысить ресурс двигателя и его экономичность. Описан опыт по её приготовлению, представлены методы, позволяющие провести её оценку. Исходя из понимания того, что мировые топливно-энергетические запасы не безграничны, цены стабильно поднимаются вверх на переработанное нефтяное топливо, то задача улучшения экологических показателей работы транспортных средств и снижения выбросов токсичных компонентов с выхлопными газами является следствием современной всемирной стратегии защиты окружающей среды. Улучшение и освоение новых типов моторного топлива и энергии, разработка и внедрение эффективных технологий и другие пути решения энергетических и экологических проблем возможны только на базе глубокого научного подхода и экспериментальных исследований. Каждый из предлагаемых видов 
альтернативных топлив, а также методов их получения и применения имеет свои преимущества и недостатки. Поэтому для выбора рациональных вариантов перспективного обеспечения топливом транспортной энергетике важно ранжировать такие топлива по их возможной эффективности в сравнении с традиционными топливами, полученных из нефтяного сырья. Сложность задачи заключается в том, что здесь тесно переплетаются технические, экологические, экономические и ресурсные факторы, которые нуждаются в комплексном и системном учете. Проводились опыты по получению стабильных бензино-этанольных эмульсий. Так как эмульсии обладают расслаивающим эффектом в смесь вводились эмульгаторы, предотвращающие расслаивание. Процесс проводился на установке, описанной ниже. Результатами наших исследований является выбор соответствующих требованиям, таким как экологичность, стабильность, эксплуатационным требованиям эмульгаторов.

Abstract. The article provides general information about the water-fuel emulsion, that helps to reduce harmful emissions into the atmosphere, increase engine life and its efficiency. The experience of its preparation is described, methods for its estimation are presented. Based on the understanding that world fuel and energy reserves are not limitless, prices are steadily rising to refined fuel oil, the task of improving the environmental performance of vehicles and reducing emissions of toxic components with exhaust gases is a consequence of the modern global environmental protection strategy. Improvement and development of new types of motor fuel and energy, development and introduction of efficient technologies and other ways of solving energy and environmental problems are possible only on the basis of a deep scientific approach and experimental research. Each of the proposed types of alternative fuels, as well as methods for their production and use has its own advantages and disadvantages. Therefore, to select rational options for the long-term supply 
of fuel to the transport energy sector, it is important to rank such fuels according to their possible efficiency in comparison with traditional fuels derived from crude oil. The difficulty of the task lies in the fact that there are closely intertwined technical, environmental, economic and resource factors that need integrated and systematic accounting. There are conducted experiments to obtain stable gasoline-ethanol emulsions. Since the emulsions have a stratifying effect, emulsifiers were added to the mixture to prevent delamination. The process was carried out on the installation described below. The results of our research is the selection of appropriate requirements, such as environmental friendliness, stability, operational requirements of emulsifiers.

Ключевые слова: водотопливная эмульсия, эмульгирование, бензиноэтанольная эмульсия, оксигенаты, ПАВ, экологичность, топливо, стабилизаторы

Key words: water-fuel emulsion, emulsification, gasoline-ethanol mixtures, oxygenate, SAS, environmental friendliness, fuel, stabilizers

Автомобильный транспорт в настоящее время является основным потребителем нефтяного топлива, а также источником токсичных веществ. Среди главных задач, стоящих в настоящее время перед машиностроителями во всем мире, - задачи энергосбережения и экологической безопасности при работе энергетических установок с двигателями внутреннего сгорания [1-4]. При проектировании современных двигателей внутреннего сгорания особое внимание уделяется их экономичности и минимизации негативного воздействия их эксплуатации на окружающую среду $[5,6]$.

Один из путей решения данной проблемы - применение водотопливных эмульсий. Их применение позволяет снизить выбросы вредных веществ в окружающую среду, повысить ресурс двигателя и его 
экономичность, также снизить износ деталей двигателя и нагарообразование.

Водотопливная эмульсия представляет дисперсную систему, включающую в себя воду - дисперсную фазу с диаметрами капель 0,1-10 мкм, и топливо, которое является дисперсной средой. Смесь воды и топлива не является устойчивой системой. Термодинамически устойчивое состояние двух несмачивающихся жидкостей отвечает минимуму свободной поверхности, причем более тяжелая жидкость находится под более легкой [7]. Жидкости будут однородными, а следовательно их капли сливаются и укрупняются. Это происходит вследствие увеличения поверхностного натяжения, что приводит к расслоению. Для предотвращения данного процесса в смесь добавляют эмульгаторы, которые создают граничный слой между данными фазами. Эмульгатор представляет собой поверхностно-активное вещество, которое подбирают таким образом, чтобы эмульсия соответствовала следующим требованиям [8]:

- эмульгатор должен обеспечить требуемую устойчивость гетерогенной системы;

- поверхностно-активное вещество должно стабилизировать нужное количество дисперсной фазы в дисперсионной среде;

- количество поверхностно-активных веществ должно быть минимальным [9].

С целью повышения времени устойчивости водотопливных смесей были проведены опыты по получению бензино-этанольных эмульсий. Введение в бензин этанола требует обязательного наличия в его составе стабилизирующих добавок, позволяющих гомогенизировать систему бензин - вода - спирт. Применение известных эффективных стабилизаторов класса спиртов $\mathrm{C}_{3}-\mathrm{C}_{5}$ приведет к росту себестоимости топлив и снижению их конкурентоспособности [10]. Вода и спирт выполняют функции антидетонационной добавки. Антидетонационный 
эффект при добавлении воды в бензин объясняется снижением температуры в камере сгорания из-за поглощения тепла при нагреве и испарении воды, характеризующейся высокими значениями теплоемкости и теплоты парообразования. Соответственно увеличивается продолжительность начальной фазы горения [11].

На сегодняшний день сохранение стабильности водотопливной эмульсии является острой практической проблемой. Эмульсии воды в топливе относятся к термодинамически неустойчивым системам. Разрушение эмульсии включает в себя три процесса:

- седиментацию, т.е. расслоение эмульсии за счет осаждения капель воды на дно, в процессе чего эмульсия становится неоднородной по высоте столба жидкости;

- флокуляцию - слипание капель или частиц, образуя скопления, т.е. флокулы;

- коалесценцию - слияние мелких капель в крупные с последующей седиментацией.

Если топливо легче, то вышеописанные процессы будут протекать быстрее. Водотопливные эмульсии, основой которых является бензин, характеризуются малой вязкостью и практически не содержат природных поверхносто-активных веществ (ПАВ), расслаиваются в течение нескольких секунд. Только при добавлении эмульгирующих добавок повышается стабильность эмульсии в несколько раз.

В том случае, если водотопливная эмульсия относительно стабильна, сохраняется опасность ее расслоения в топливопроводах под действием капиллярной силы. В связи с этим пуск и остановку двигателя следует проводить на чистом топливе, переключаясь на эмульсию с выходом на режим. Также следует учитывать, что в прогретом двигателе расслоение эмульсии протекает быстрее, чем в лабораторных условиях.

Для приготовления бензино-этанольной эмульсии были использованы автомобильный бензин АИ- 80 , вода и этанол. Содержание бензина 
$80 \%$ (об.), этанола $10 \%$ (об.) и воды $10 \%$ (об.). Также в смесь вводились эмульгаторы, такие как пентол, неонол, ОП-7, ОП-10, синтанол, интанол, смесь СЖК, кубовые остатки производства бутиловых спиртов и изопрена. Готовая эмульсия хранилась в темном месте, в стеклянной закрытой бутылке, при температуре $20-25^{\circ} \mathrm{C}$. Эмульсия, стабильность которой сохранялась в течение 24 ч, считалась нерасслаивающейся.

Схема лабораторной установки представлена на рисунке 1.

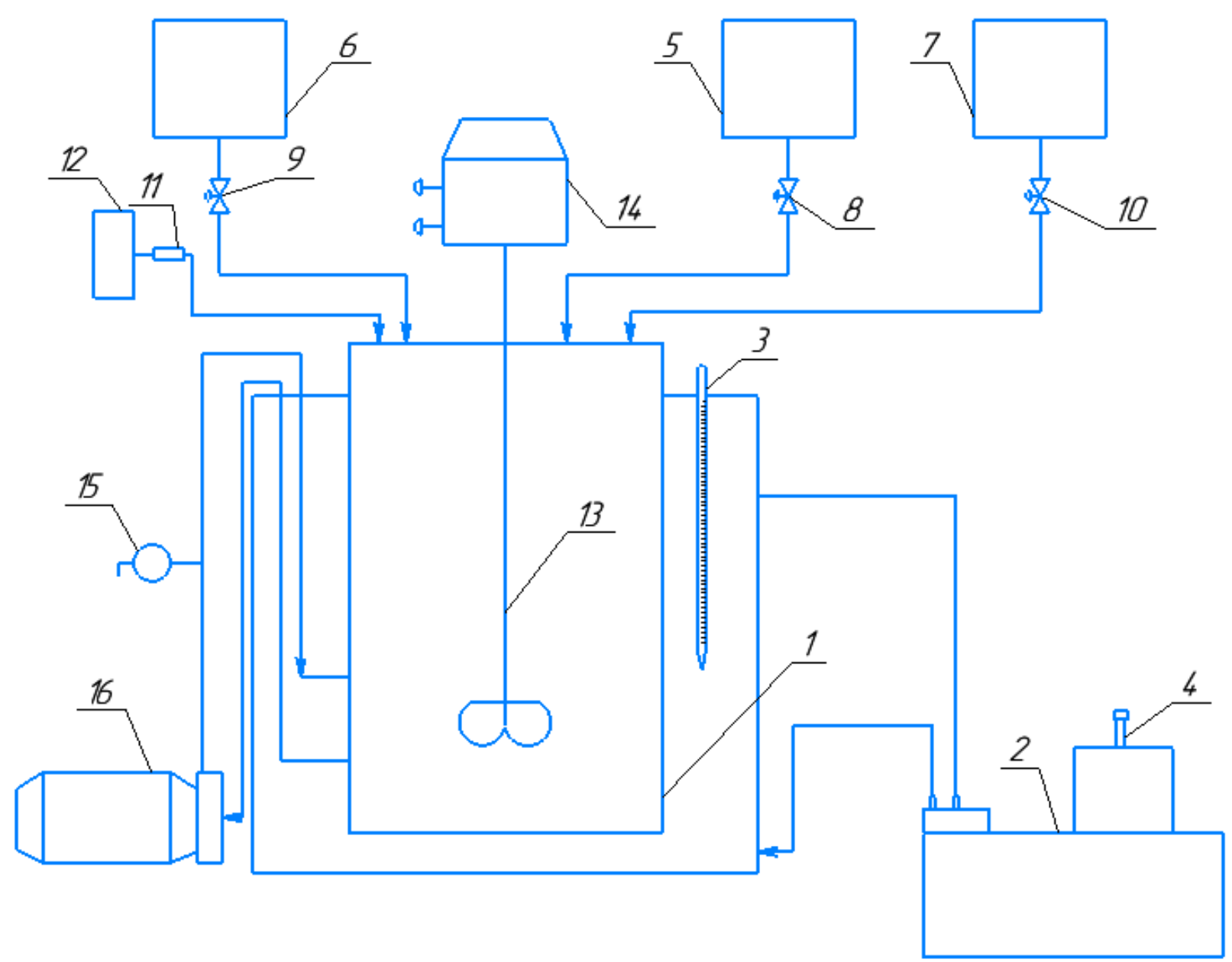

1 - емкость для эмульгирования; 2 - термостат; 3 , 4 - термометры, 5, 6, 7 - емкости; 8, 9, 10 - вентили; 11 - шприц; 13 - мешалки; 14 - электродвигатель; 15 - пробоотборник; 16 - насос

Рисунок 1. Схема лабораторной установки для эмульгирования бензино-этанольных смесей 
Приготовление бензино-этанольной эмульсии происходит в сосуде 1 , емкостью 500 мл, термостатируемой термостатом 2. Температура воды в термостате фиксируется термометром 3 и регулируется при помощи контактного термометра 4.

Этанол, вода и автомобильный бензин подаются соответственно из емкостей 5, 6 и 7. Для регулировки их расхода служат вентили 8, 9 и 10. Подача эмульгатора в сосуд 1 осуществляется при помощи медицинского шприца 11 и специального дозирующего устройства 12. Перемешивание жидких фаз осуществляется с помощью пропеллерной мешалки 13 , которая работает от электродвигателя 14. Скорость вращения мешалки 1650 об/мин, регулируется при помощи ЛАТРа. Для дополнительного перемешивания и повышения однородности эмульсии, её дисперсности, а также для удобства отбора проб (проба отбирается через кран 15) смесь дополнительно перекачивается насосом 16 производительностью 57,6 л/ч и возвращается вновь в емкость

После получения водотопливной эмульсии необходимо проводить оценку эффективности процесса диспергирования. Она была проведена спектрофотометрическим методом. Этот метод позволяет осуществлять быстрый контроль качества эмульсии. Для определения оптической плотности бензино-этанольной эмульсии применялся спектрофотометр «ПЭ-5300ВИ», который является наиболее точным и чувствительным оптическим прибором.

Для сравнения дисперсности полученных эмульсий регистрировалась их оптическая плотность при длине волны излучения $\lambda=400$ нм. Толщина слоя измеряемой эмульсии 0,05 нм.

Результаты экспериментов при различных эмульгаторах приведены в таблице 1. 
Таблица 1. Подбор эмульгатора бензино-этанольной эмульсии

\begin{tabular}{|c|c|c|c|c|c|c|c|}
\hline \multirow{2}{*}{$\begin{array}{l}\text { Наименование } \\
\text { эмульгатора }\end{array}$} & \multirow{2}{*}{$\begin{array}{l}\text { Температура } \\
\text { кипения, }{ }^{\circ} \mathrm{C}\end{array}$} & \multicolumn{6}{|c|}{ Количество добавляемого реагента, \% (масс.) } \\
\hline & & 0,05 & 0,1 & 0,2 & 0,5 & 1,0 & 5,0 \\
\hline Пентол & 138 & расслоилось & \multicolumn{5}{|c|}{ не расслоилось } \\
\hline Неонол & свыше 280 & \multicolumn{6}{|c|}{ не расслоилось } \\
\hline Синтанол & $220-250$ & \multicolumn{2}{|c|}{ расслоилось } & \multicolumn{4}{|c|}{ не расслоилось } \\
\hline Интанол & $180-250$ & расслоилось & \multicolumn{5}{|c|}{ не расслоилось } \\
\hline ОП-7 & 118 & \multicolumn{4}{|c|}{ расслоилось } & \multicolumn{2}{|r|}{$\mathrm{He}$} \\
\hline ОП-10 & 105 & \multicolumn{4}{|c|}{ расслоилось } & \multicolumn{2}{|r|}{ не } \\
\hline $\begin{array}{l}\text { Кубовый остаток } \\
\text { производства } \\
\text { бутиловых } \\
\text { спиртов (фр.195- } \\
\text { 290) }\end{array}$ & $120-330$ & \multicolumn{6}{|c|}{ расслоилось } \\
\hline $\begin{array}{l}\text { «Флотореагент» } \\
\text { - кубовый } \\
\text { остаток } \\
\text { производства } \\
\text { изопрена } \\
\left(\text { фр. } 217-338^{\circ} \mathrm{C}\right)\end{array}$ & $271-338$ & \multicolumn{5}{|c|}{ расслоилось } & $\begin{array}{c}\text { не } \\
\text { рассло- } \\
\text { илось }\end{array}$ \\
\hline
\end{tabular}

\section{Вывод}

В заключение можно отметить, что кубовый остаток производства изопрена - «флотореагент» проявляет эмульгирующую способность для бензино-этанольных смесей. Однако использовать его как эмульгатор нецелесообразно, так как это связано с его большим содержанием в топливной эмульсии, а также с его высокой температурой выкипания (271-338 ㄷ). Для исследования кинетики эмульгирования были выбраны выпускаемые нашей промышленностью ПАВы: пентол, неонол, интанол. Выбранные ионогенные ПАВы соответствуют требованиям, таким как соизмеримая температура кипения и оптимальная дозировка, гарантирующая стабильность эмульсий в течение продолжительного времени. Эффективная концентрация варьируется от $0,1 \%$ до 0,2 \%, исходя из таблицы 1. Этанол как альтернативное топливо имеет ряд преимуществ: большую растворимость в углеводородном топливе и малую гигроскопичность [12]. Было установлено, что присутствие небольшого количества этанола в бензине не приводит к ухудшению 
эксплуатационных характеристик двигателя внутреннего сгорания и не требует дополнительной регулировки карбюратора, также наряду с этим снижаются выбросы СО.

\section{Вывод}

Введение оксигенатов в автомобильные бензины приводит к положительным показателям антидетонационных свойств и температур кипения, улучшая фракционный состав бензинов. Рекомендуемая концентрация оксигенатов в бензинах составляет 3-15 \% (об.) и выбирается с таким расчетом, чтобы содержание кислорода в топливе не превышало $2,7 \%$ [11, 13]. В результате установлено, что такое количество оксигенатов, несмотря на их более низкую по сравнению с бензином из нефти теплотворную способность, не влияет на мощностные характеристики двигателей внутреннего сгорания.

\section{Список использованных источников}

1. Патров Ф.В., Вахромеев О.С. Использование водотопливной эмульсии при эксплуатации судовых ДВС // Судовые энергетические установки и машинно-движительные комплексы. 2009. С. 223.

2. Сидоров Г.М. Разработка и внедрение энергосберегающей технологии фракционирования нефтяных смесей с использованием сложных колонн с частично связанными потоками: дис. ... д-ра техн. наук. Уфа: УГНТУ, 1999. 317 с.

3. Патент 2059688 Российская Федерация, С 10 G 69/02. Способ переработки нефтяных фракций / Сидоров Г.М., Деменков В.Н., Кондратьев А.А., Баланич А.А., Демьяненко Е.А., Карибов А.К., Бирюков Ф.И., Оразсахатов К.С., Зорькин А.М., Грасюков И.И., Шиверский К.В. 9393017429, Заявлено 05.04.1993. 
4. Баланич А.А., Сидоров Г.М., Деменков В.Н. Нефтепереработка и нефтехимия // Научно-технические достижения и передовой опыт. 1994. № 3. C. 13.

5. Новиков Л.А. Основные направления создания малотоксичных транспортных двигателей // Двигателестроение. 2002. № 2. С. 23-27.

6. Малов Р.В. Механизм воспламенения низкоцетановых дизельных топлив // Автомобильная промышленность. 1994. № 10. С. 11-14.

7. Шерман Ф. Эмульсии. Л.: Химия, 1972. 447 с.

8. Иванов А.С. Водотопливная эмульсия для двигателей внутреннего сгорания // Вестник Московского государственного агроинженерного университета им. В.П. Горячкина. 2009. С. 66-68.

9. Митькина С.А., Гильмутдинов А.Т. Характер улучшения качественных характеристик топлива путем получения эмульсионных высокооктановых композиций // Башкирский химический журнал. 2009. № 1. C. $76-81$.

10. Климентова Г.Ю., Маврин В.Ю. Низкотемпературные свойства спиртосодержащих топлив // Вестник КГТУ. 2013. Т. 16. № 6. С. 206-208.

11. Данилов А.М. Применение присадок в топливах для автомобилей: справочник. М.: Химия, 2000. 232 с.

12. Танатаров М.А., Гильмутдинов А.Т. Перспективы и проблемы альтернативных моторных топлив. Уфа: Изд-во УГНТУ, 1998. $131 \mathrm{c.}$

13. Данилов А.М., Каминский Э.Ф., Хавкин В.А. Альтернативные топлива: достоинства и недостатки. Проблемы применения // Российский химический журнал. 2003. № 6. T. XLVII. C. 4-11. 


\section{References}

1. Patrov F.V., Vakhromeev O.S. Ispol'zovanie vodotoplivnoi emul'sii pri ekspluatatsii sudovykh DVS [Urgency of the Use of Water-Fuel Emulsion in Exploitation of Marine Ice]. Sudovye energeticheskie ustanovki i mashinnodvizhitel'nye kompleksy-Ship Power Plants and Engine Propulsion Systems, 2009, 223 p. [in Russian].

2. Sidorov G.M. Razrabotka $i$ vnedrenie energosberegayushchei tekhnologii fraktsionirovaniya neftyanykh smesei s ispol'zovaniem slozhnykh kolonn s chastichno svyazannymi potokami: dis. ... d-ra tekhn. nauk [Development and Implementation of Energy-Saving Technology for the Fractionation of Oil Mixtures Using Complex Columns with Partially Connected Flows: dis. ... Dr. Engin. Sci.]. Ufa, UGNTU Publ., 1999. 317 p. [in Russian].

3. Sidorov G.M., Demenkov V.N., Kondrat'ev A.A., Balanich A.A., Dem'yanenko E.A., Karibov A.K., Biryukov F.I., Orazsakhatov K.S., Zor'kin A.M., Grasyukov I.I., Shiverskii K.V. Sposob pererabotki neftyanykh fraktsii [Method for Oil Fractions Processing]. Patent RF, No. 2059688, 1993. [in Russian].

4. Balanich A.A., Sidorov G.M., Demenkov V.N. Neftepererabotka i neftekhimiya [Refining and Petrochemicals]. Nauchno-tekhnicheskie dostizheniya i peredovoi opyt - Scientific and Technical Achievements and Best Practices, 1994, № 3, pp. 13. [in Russian].

5. Novikov L.A. Osnovnye napravleniya sozdaniya malotoksichnykh transportnykh dvigatelei [Principal Directions of Engine Emission Behavior Improvement]. Dvigatelestroenie - Dvigatelestryeniye, 2002, No. 2, pp. 23-27. [in Russian]. 
6. Novikov L.A. Osnovnye napravleniya sozdaniya malotoksichnykh transportnykh dvigatelei [Principal Directions of Engine Emission Behavior Improvement]. Dvigatelestroenie - Dvigatelestryeniye, 2002, No. 2, pp. 23-27. [in Russian].

7. Sherman F. Emul'sii [Emulsions]. Leningrad, Khimiya Publ., 1972, 447 p. [in Russian].

8. Ivanov A.S. Vodotoplivnaya emul'siya dlya dvigatelei vnutrennego sgoraniya [Water-Fuel Emulsion for Internal Combustion Engines]. Vestnik FGOU VPO «Moskovskii gosudarstvennyi agroinzhenernyi universitet im. V.P. Goryachkina»-Vestnik of the Federal State Educational Institution of Higher Professional Education «Moscow State Agroengineering University named after V.P. Goryachkin», 2009, pp. 66-68. [in Russian].

9. Mit'kina S.A., Gil'mutdinov A.T. Kharakter uluchsheniya kachestvennykh kharakteristik topliva putem polucheniya emul'sionnykh vysokooktanovykh kompozitsii [The Improvement of Fuel Qualitative Characteristics by Reception High Antiknock Emulsion Composition]. Bashkirskii khimicheskii zhurnal - Bashkir Chemical Journal, 2009, No. 1, pp. 76-81. [in Russian].

10. Klimentova G.Yu., Mavrin V.Yu. Nizkotemperaturnye svoistva spirtosoderzhashchikh topliv [The Low-Temperature Properties of Alcohol Fuels]. Vestnik KGTU - Vestnik KGTU, 2013, Issue 16, No. 6, pp. 206-208. [in Russian].

11. Danilov A.M. Primenenie prisadok $v$ toplivakh dlya avtomobilei: Spravochnik [Application of the Additives in Fuels for Cars: Reference Book], Moscow, Khimiya Publ., 2000. 180 p. [in Russian].

12. Tanatarov M.A., Gil'mutdinov A.T. Perspektivy $i$ problemy al'ternativnykh motornykh topliv [Perspectives and Problems of Alternative Motor Fuels].Ufa, UGNTU Publ., 1998, 131 p. [in Russian]. 
13. Danilov A.M., Kaminskii E.F., Khavkin V.A. Al'ternativnye topliva: dostoinstva i nedostatki. Problemy primeneniya [Alternative Fuels: Merits and Demerits. Application Problems]. Rossiiskii Khimicheskii Zhurnal - Russian Chemical Journal, 2003, vol. XLVII, No. 6, pp. 4-11. [in Russian].

\section{Сведения об авторах}

\section{About the authors}

Гареев Тимур Рамилевич, магистрант кафедры «Технология нефти и газа», УГНТУ, г. Уфа, Российская Федерация

Timur R. Gareev, Under-Graduate Student of oil and gas Technology Department, USPTU, Ufa, Russian Federation

e-mail: timur285@mail.ru

Гильмутдинов Амир Тимерьянович, д-р техн. наук, профессор, профессор кафедры «Технология нефти и газа», УГНТУ, г. Уфа, Российская Федерация

Amir T. Gilmutdinov, Doctor of Engineering Sciences, Associated Professor, Professor of Oil and Gas Technology Department, USPTU, Ufa, Russian Federation

e-mail: amir55g@mail.ru

Лапшин Игорь Геннадиевич, аспирант кафедры «Технология нефти и газа», УГНТУ, г. Уфа, Российская Федерация

Igor G. Lapshin, Post-Graduate Student of Oil and Gas Technology Department, USPTU, Ufa, Russian Federation

e-mail: klods2010@yandex.ru 